\title{
Analysis of genetic and non-genetic factors that affect the QTC interval in a Mongolian population: the GENDISCAN study
}

\author{
Sun-Wha $\mathrm{Im}^{1}$, Mi Kyeong Lee ${ }^{2,3}$, \\ Hee Jeong Lee ${ }^{3}$, Se-II Oh${ }^{4}$, Hyung-Lae Kim ${ }^{5}$, \\ Joohon Sung ${ }^{3}$, Sung-ll $\mathrm{Cho}^{3}$, \\ Jeong-Sun Seo ${ }^{1,6,7}$ and Jong-II Kim ${ }^{1,2,6,7}$ \\ ${ }^{1}$ Department of Biochemistry and Molecular Biology \\ Seoul National University College of Medicine \\ Seoul 110-799, Korea \\ ${ }^{2}$ Psoma Therapeutics, Inc \\ Seoul 153-023, Korea \\ ${ }^{3}$ Department of Epidemiology \\ Graduate School of Public Health and \\ Institute of Health and Environment \\ ${ }^{4}$ Department of Internal Medicine \\ Seoul National University College of Medicine \\ Seoul 110-799, Korea \\ ${ }^{5}$ Department of Biochemistry \\ Ewha Womans University School of Medicine \\ Seoul 158-710, Korea \\ ${ }^{6}$ ILCHUN Genomic Medicine Institute \\ Medical Research Center \\ Seoul National University \\ Seoul 110-799, Korea \\ ${ }^{7}$ Corresponding authors: Tel, 82-2-740-8246; \\ Fax, 82-2-741-5423; E-mail, jeongsun@snu.ac.kr (J.S. Seo) \\ Tel: 82-2-740-8421; Fax: 82-2-741-5423 \\ E-mail: jongil@ snu.ac.kr (J.I. Kim) \\ DOI 10.3858/emm.2009.41.11.090
}

Accepted 13 July 2009

Abbreviations: BMI, body mass index; DBP, diastolic blood pressures; LQTS, long QT syndrome; SBP, systolic blood pressures; STR, short tandem repeat

\begin{abstract}
The QTc interval is a complex quantitative trait and a strong prognostic indicator of cardiovascular mortality in general, healthy people. The aim of this study was to identify non-genetic factors and quantitative trait loci that govern the QTC interval in an isolated Mongolian population. We used multiple regression analysis to determine the relationship between the QTc interval and non-genetic factors including height, blood pressure, and the plasma lipid level. Whole genome linkage analyses were performed to reveal quantitative trait lo-
\end{abstract}

ci for the QTc interval with 349 microsatellite markers from 1,080 Mongolian subjects. Among many factors previously known for association with the QTc interval, age, sex, heart rate, QRS duration of electrocardiogram and systolic blood pressure were also found to have influence on the QTc interval. A genetic effect for the QTC interval was identified based on familial correlation with a heritability value of 0.31 . In a whole genome linkage analysis, we identified the four potential linkage regions $7 q 31-34,5 q 21,4 q 28$, and $2 q 36$.

Keywords: electrocardiography; linkage (genetics); long QT syndrome; quantitative trait, heritable; quantitative trait loci; regression analysis

\section{Introduction}

An individual with a prolonged QTC interval is prone to ventricular arrhythmia. The QTc interval is also a strong prognostic indicator of cardiovascular mortality in patients both with and without cardiac disease (Peters et al., 1990; Algra et al., 1991; Siscovick et al., 1996). Several epidemiological studies (Schouten et al., 1991; Dekker et al., 1994, 2004; De Bruyne et al., 1999) have reported a relationship between QTc interval prolongation and increased risk of cardiovascular mortality in healthy individuals, although controversy exists (Goldberg et al., 1991).

The QTc interval is a complex quantitative trait. Many factors, both genetic and non-genetic, affect the QTc interval. The heritability of the QTc interval ranges between 0.25 and 0.40 (Russell et al., 1998; Friedlander et al., 1999; Carter et al., 2000; Newton-Cheh et al., 2005), and at least seven genes involved in the congenital long QT syndrome (LQTS) have been identified (Keating et al., 1991a; 1991b; Jiang et al., 1994; Schott et al., 1995; Wang et al., 1995; Splawski et al., 2000; Shah et al., 2005). Six of these genes encode potassium or sodium ion channel proteins. The seventh gene, the ANK2 gene, encodes the structural protein ankyrin-B. The molecular mechanisms of these rare form Mendelian diseases have been identified. However, QTc interval values in the general population can not be fully explained by these LQTS genes. Therefore, it is possible that there are other genes that regulate the QTc interval. Most previous 
Table 1. Ethnic composition of the study population.

\begin{tabular}{lc}
\hline Ethnicity & Number (\%) \\
\hline Khalkha & $1,055(80.6)$ \\
Uriankhai & $126(9.6)$ \\
Dorwod & $71(5.4)$ \\
Others $^{*}$ & $57(4.4)$ \\
Total & $1,309(100)$
\end{tabular}

*Other 10 ethinicities: Bayad, Buryat, Darhad, Hoton, Kazakh, Oold, Oros, Shanga, Tuva, and Zahchi.

studies focused on candidate regulation genes (Busjahn et al., 1999; Liu et al., 2002) already known as LQTS genes, but in order to identify unknown genes that regulate the QTc interval in the general population, a population-based whole genome study is necessary.

An isolated population is appropriate for identifying genes that are responsible for complex traits because such a population reduces genetic heterogeneity and environmental diversity. Also, a large extended pedigree provides much genetic information. Mongolians, especially rural people, are regionally and genetically isolated with many large extended families.

We identified genetic factors involved in the QTC interval based on familial aggregation and heritability, and conducted a genome-wide linkage analysis with 1,080 Mongolian subjects. We also evaluated the association of many non-genetic factors with the QTc interval using multiple regression analysis.

\section{Results}

Mongolian people comprise several major and many minor tribes. Table 1 shows the tribal distribution of our study participants, including three larger tribes and ten smaller ones. The Khalkha is the majority tribe in Mongolia and in our study. Table 2 shows the sex-specific mean \pm SD of age, heart rate, QRS duration, and other characteristics of the study participants. The average age of our population was 29 years with females being slightly older than males. Values for heart rate, height, plasma total cholesterol, and fasting plasma glucose revealed significant differences between the two sexes.

The QTc interval exhibited a normal distribution within each sex group (Figure 1). The mean QTC interval was $421.54 \mathrm{~ms}$ in total, $415.86 \mathrm{~ms}$ in males, and $425.89 \mathrm{~ms}$ in females. The mean QTC interval for females was significantly longer than for males $(P<0.0001)$. As seen in Table 3 , the QTC interval decreased with age until the twenties, and then increased afterward. The difference in the QTC interval between females and males was significant for ages between the teens to the fifties (asterisks, $P<0.05$ ), but not for ages $<10$ or $\geq$ 60 . Table 3 also shows the age- and sex- specific distribution of abnormal QTc intervals. Generally, $440 \mathrm{~ms}$ is accepted as the upper limit of a normal QTc interval (Garson, 1993). Using this criterion, among 1,074 individuals (466 men and 608 women), 219 (61 men and 158 women) were classified as abnormal. The proportion of persons

Table 2. Characteristics of subjects.

\begin{tabular}{|c|c|c|c|c|c|c|}
\hline & \multicolumn{2}{|r|}{ Total } & \multicolumn{2}{|r|}{ Male } & \multicolumn{2}{|r|}{ Female } \\
\hline & $n$ & Mean \pm SD & $n$ & Mean \pm SD & $n$ & Mean \pm SD \\
\hline Age $(y)$ & 1,074 & $29.39 \pm 18.04$ & 466 & $27.60 \pm 18.04$ & 608 & $30.76 \pm 17.93^{*}$ \\
\hline Heart rate $(/ \mathrm{min})$ & 1,070 & $70.37 \pm 12.74$ & 465 & $68.65 \pm 12.51$ & 605 & $71.69 \pm 12.77^{*}$ \\
\hline QRS duration (ms) & 1,070 & $91.09 \pm 14.04$ & 465 & $96.79 \pm 14.38$ & 605 & $86.71 \pm 12.07^{\star}$ \\
\hline Height $(\mathrm{cm})$ & 1,074 & $151.29 \pm 16.22$ & 466 & $153.75 \pm 19.05$ & 608 & $149.41 \pm 13.38^{*}$ \\
\hline Weight (kg) & 1,074 & $51.86 \pm 17.83$ & 466 & $52.38 \pm 20.11$ & 608 & $51.47 \pm 15.86$ \\
\hline $\mathrm{SBP}(\mathrm{mmHg})$ & 1,073 & $115.70 \pm 24.75$ & 465 & $115.01 \pm 23.75$ & 608 & $116.23 \pm 25.50$ \\
\hline $\mathrm{DBP}(\mathrm{mmHg})$ & 1,072 & $78.65 \pm 15.81$ & 464 & $77.70 \pm 15.06$ & 608 & $79.38 \pm 16.33$ \\
\hline BMI $\left(\mathrm{kg} / \mathrm{m}^{2}\right)$ & 1,074 & $21.91 \pm 4.91$ & 466 & $21.14 \pm 4.60$ & 608 & $22.50 \pm 5.07^{\star}$ \\
\hline FAT $(\%)$ & 1,068 & $25.37 \pm 8.58$ & 463 & $20.22 \pm 6.72$ & 605 & $29.31 \pm 7.73^{*}$ \\
\hline TG (mg/dl) & 1,028 & $67.32 \pm 35.30$ & 440 & $68.04 \pm 37.94$ & 585 & $66.78 \pm 33.21$ \\
\hline Chol (mg/dl) & 1,024 & $150.34 \pm 33.46$ & 439 & $147.74 \pm 32.97$ & 585 & $152.29 \pm 33.73^{*}$ \\
\hline HDL (mg/dl) & 1,024 & $50.73 \pm 12.82$ & 439 & $49.41 \pm 11.97$ & 585 & $51.71 \pm 13.35^{*}$ \\
\hline LDL (mg/dl) & 1,024 & $86.15 \pm 25.56$ & 439 & $84.72 \pm 25.60$ & 585 & $87.21 \pm 25.51$ \\
\hline Glu (mg/dl) & 1,024 & $87.81 \pm 14.56$ & 439 & $89.56 \pm 13.46$ & 585 & $86.49 \pm 15.20^{*}$ \\
\hline
\end{tabular}

SBP, systolic blood pressure; DBP, diastolic blood pressure; BMI, body mass index; Chol, plasma total cholesterol; HDL, HDL-cholesterol; LDL, LDL-cholesterol; TG, fasting plasma triglycerides; Glu, fasting plasma glucose. " significant difference by $\operatorname{sex} P<.05$. 
A

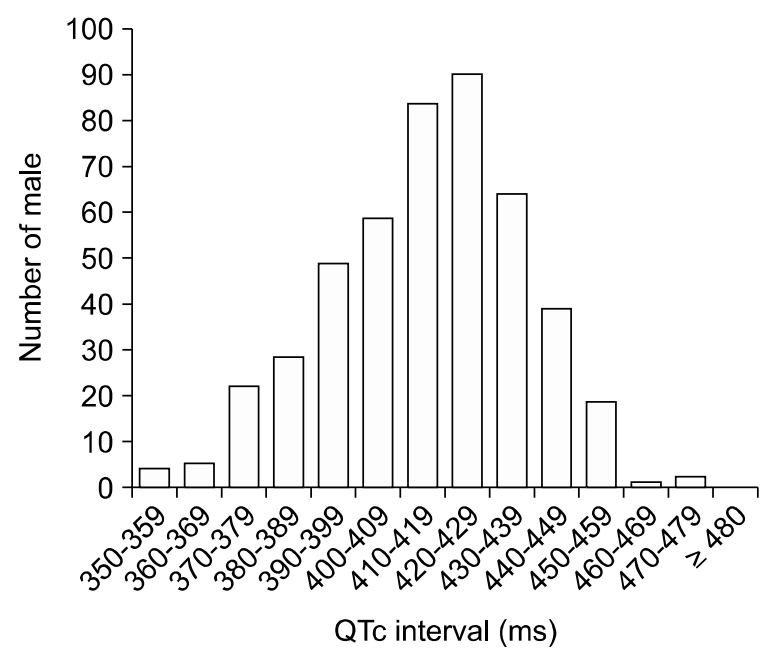

B

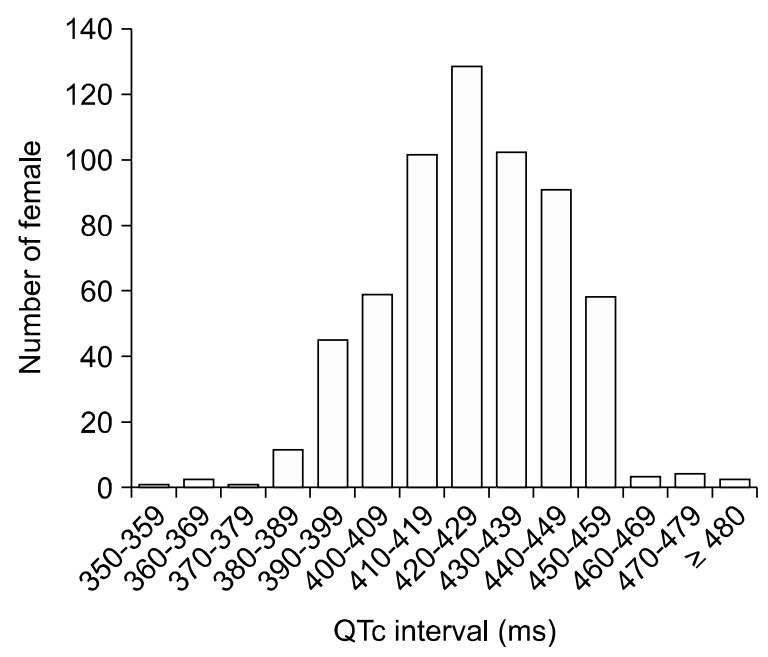

Figure 1. Distribution of the QTc interval by sex. QTc intervals for males (A) and females (B) show normal distributions within each sex group.

with an elongated QTc interval was higher in females than in males because the mean QTC interval for females was longer than for males. This pattern was observed in every age range.

Table 4 summarizes results of the multiple regression analysis using many factors that may affect the QTc interval, including age, sex, electrocardiogram findings (heart rate, QRS duration), height, weight, BMI, fat, blood pressure (systolic and diastolic), lipid (TG, total cholesterol, HDL, LDL), and fasting plasma glucose. In a univariate analysis, all of these factors showed significant association with the QTc interval (data not shown), but in a multiple regression analysis, the QTc interval was influenced only by age $\times$ sex, age ${ }^{2} \times$ sex, systolic blood pressure, heart rate, height, and QRS duration.

The genetic component of a phenotype can be assumed based on familial aggregation and heritability. Based on results of the familial correlation study (Table 5), among the main types of familial relationships (spouse-spouse, parent-offspring, and sibling-sibling), the sibling-sibling pair showed the most significant correlation and the spouse-spouse pair showed the least correlation, implying a genetic effect for the QTc interval.

The heritability of the QTC interval, adjusted for age and sex, was 0.31 , suggesting a moderate genetic effect. A heritability estimate of 0.31 for the adjusted QTc interval indicates that $31 \%$ of the inter-individual variance in the QTc interval duration is attributable to additive genetic effects.

Table 6 and Figure 2 show results of a genome-wide multipoint linkage analysis of the QTC interval using the variance component method in SOLAR across 22 autosomes. Age and sex were

Table 3. Age- and sex-specific distribution of the QTc and abnormal QTc intervals ( $>=440 \mathrm{~ms}$ ).

\begin{tabular}{|c|c|c|c|c|c|c|c|c|c|}
\hline \multirow{2}{*}{$\begin{array}{l}\text { Age } \\
\text { Goup, y }\end{array}$} & \multicolumn{3}{|c|}{ Total } & \multicolumn{3}{|c|}{ Male } & \multicolumn{3}{|c|}{ Female } \\
\hline & $n$ & Mean \pm SD & $\begin{array}{c}\geq 440 \mathrm{~ms} \\
n(\%)\end{array}$ & $n$ & Mean \pm SD & $\begin{array}{c}\geq 440 \mathrm{~ms} \\
n(\%)\end{array}$ & $n$ & Mean \pm SD & $\begin{array}{c}\geq 440 \mathrm{~ms} \\
n(\%)\end{array}$ \\
\hline $0-9$ & 116 & $426.77 \pm 17.55$ & $28(24.14)$ & 61 & $426.54 \pm 17.62$ & $14(22.95)$ & 55 & $427.02 \pm 17.62$ & $14(25.45)$ \\
\hline $10-19$ & 333 & $422.31 \pm 19.56$ & 71 (21.32) & 159 & $419.37 \pm 20.04$ & $28(17.61)$ & 174 & $425.00 \pm 17.75^{*}$ & $43(24.71)$ \\
\hline $20-29$ & 132 & $412.11 \pm 21.86$ & $16(12.12)$ & 53 & $403.94 \pm 19.55$ & $2(3.77)$ & 79 & $417.58 \pm 21.74^{*}$ & $14(17.72)$ \\
\hline $30-39$ & 185 & $420.22 \pm 21.62$ & 35 (18.92) & 65 & $407.28 \pm 20.78$ & $3(4.62)$ & 120 & $427.23 \pm 18.70^{*}$ & 32 (26.67) \\
\hline $40-49$ & 147 & $420.50 \pm 20.80$ & $25(17.01)$ & 69 & $410.84 \pm 20.35$ & $4(5.80)$ & 78 & $429.04 \pm 17.23^{*}$ & $21(26.92)$ \\
\hline $50-59$ & 76 & $425.09 \pm 20.32$ & $23(30.26)$ & 25 & $416.64 \pm 20.78$ & $4(16.00)$ & 51 & $429.24 \pm 18.94^{*}$ & $19(37.25)$ \\
\hline $60-69$ & 60 & $422.67 \pm 21.09$ & $11(18.33)$ & 25 & $421.00 \pm 23.91$ & $3(12.00)$ & 35 & $423.86 \pm 19.11$ & $8(22.86)$ \\
\hline$\geq 70$ & 25 & $439.28 \pm 27.43$ & $10(40.00)$ & 9 & $435.78 \pm 10.59$ & $3(33.33)$ & 16 & $441.25 \pm 33.65$ & 7 (43.75) \\
\hline Total & 1,074 & $421.54 \pm 21.02$ & $219(20.39)$ & 466 & $415.86 \pm 21.57$ & $61(13.09)$ & 608 & $425.89 \pm 19.51^{*}$ & 158 (25.99) \\
\hline
\end{tabular}

* Significant difference by $\operatorname{sex} P<.05$. 
Table 4. Results of multiple regression analyses for the QTC interval.

\begin{tabular}{lccr}
\hline \multicolumn{1}{c}{ Variable } & $\begin{array}{c}\text { Parameter } \\
\text { estimate }\end{array}$ & $\begin{array}{c}\text { Standard } \\
\text { error }\end{array}$ & $P$ value \\
\hline Age $\times$ Sex & 0.356 & 0.060 & $<.0001$ \\
Age $^{2} \times$ Sex & -0.003 & 0.001 & 0.0003 \\
Systolic blood & 0.112 & 0.032 & 0.0005 \\
pressure & & & \\
Heart rate & 0.630 & 0.051 & $<.0001$ \\
Height & -0.272 & 0.046 & $<.0001$ \\
QRS Duration & 0.100 & 0.045 & 0.0270 \\
\hline
\end{tabular}

used as covariates in this analysis. The highest LOD score was 2.0 for the chromosome $7 q 31$ region (Figure 2 and 3 ). The second and third peaks represent chromosomes $5 \mathrm{q} 21$ and $4 \mathrm{q} 28$, where the maximum LOD scores were 1.9 for both peaks. An additional narrow peak was identified for chromosome $2 q 36$ with a maximum LOD score of 1.7.

\section{Discussion}

Although QTc interval values for various populations have been reported, most studies have been performed with Westerners and there is scant information for Asians. Racial differences in the QTc interval have been reported (Vitelli et al., 1998; Grandinetti et al., 2005); The QTc interval is longer in Asians than in Caucasians, and longer in Caucasians than in African-Americans. However, our results show the mean QTc interval values in males and females are 415.82 and 425.91 , respectively, and the proportion of prolonged QTc intervals is $13.09 \%$ in males and $25.99 \%$ in females. This is similar to results in other studies (Friedlander et al., 1999; Crow et al., 2003; Benoit et al., 2005).
Table 5. Familial correlations for the QTC interval.

\begin{tabular}{lcrr}
\hline & $n$ & \multicolumn{1}{c}{ QTc } & \multicolumn{1}{c}{ COV_5* } \\
\hline Mother - father & 140 & 0.0591 & 0.0390 \\
Father - son & 175 & -0.1121 & -0.0192 \\
Mother - son & 303 & 0.1804 & 0.2415 \\
Father - daughter & 163 & 0.1467 & 0.1510 \\
Mother - daughter & 341 & 0.1018 & 0.1046 \\
Parent - offspring & 982 & 0.0819 & 0.1285 \\
Brother - brother & 109 & 0.2829 & 0.2781 \\
Brother - sister & 282 & 0.1781 & 0.2188 \\
Sister - sister & 139 & 0.1337 & 0.1334 \\
Sibling - sibling & 530 & 0.1825 & 0.2091 \\
\hline
\end{tabular}

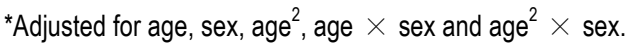

However, direct comparison is impossible because there are differences in study design and population composition. Several studies have reported on the heritability of the QTc interval with results ranging from 0.25 to 0.40 (Russell et al., 1998; Friedlander et al., 1999; Carter et al., 2000; Newton-Cheh et al., 2005). Our heritability value of 0.31 is comparable.

As seen in Table 3, the QTc interval increases with age in adults. Although well known, the mechanism of this increase is not known (Reardon and Malik, 1996; Mangoni et al., 2003). The difference in the QTc interval by sex is significant only in middle age (aged 10-59) and may be a hormonal effect.

Many factors are known to be associated with the QTc interval, including age and sex, which are well known, and heart rate, height, weight, blood pressure (systolic and diastolic), lipid (TG, total cholesterol, HDL, LDL), fasting plasma glucose, which are controversial (Dekker et al., 1994, 2004; De Bruyne et al., 1999; Mangoni et al., 2003; Benoit et al., 2005). Our results showed that weight, BMI, fat, diastolic blood pressure, lipid (TG,

Table 6. Results of linkage analyses for the QTC interval.

\begin{tabular}{|c|c|c|c|c|c|c|}
\hline Age & $\mathrm{N}$ & $\begin{array}{l}\text { Maximum } \\
\text { LOD score }\end{array}$ & $\begin{array}{c}\text { Chromosome } \\
\text { (cM) }\end{array}$ & $\begin{array}{l}\text { Cytogenetic } \\
\text { location }\end{array}$ & $\begin{array}{l}\text { Nearest } \\
\text { markers }\end{array}$ & $\begin{array}{c}\text { Empirical } \\
P \text { value }\end{array}$ \\
\hline \multirow[t]{8}{*}{$5-82$} & 1,073 & 2.0 & $7(157)$ & $7 q 31$ & D7S530 & 0.0012 \\
\hline & & & & & D7S684 & \\
\hline & & 1.9 & $5(124)$ & $5 q 21$ & D5S644 & 0.0013 \\
\hline & & & & & D5S433 & \\
\hline & & 1.9 & $4(143)$ & $4 q 28$ & D4S406 & 0.0013 \\
\hline & & & & & D4S2394 & \\
\hline & & 1.7 & $2(252)$ & $2 q 36$ & D2S1363 & 0.0022 \\
\hline & & & & & D2S260 & \\
\hline \multirow[t]{2}{*}{$20-82$} & 624 & 2.4 & $7(162)$ & $7 q 34$ & D7S530 & 0.0001 \\
\hline & & & & & D7S684 & \\
\hline
\end{tabular}


A

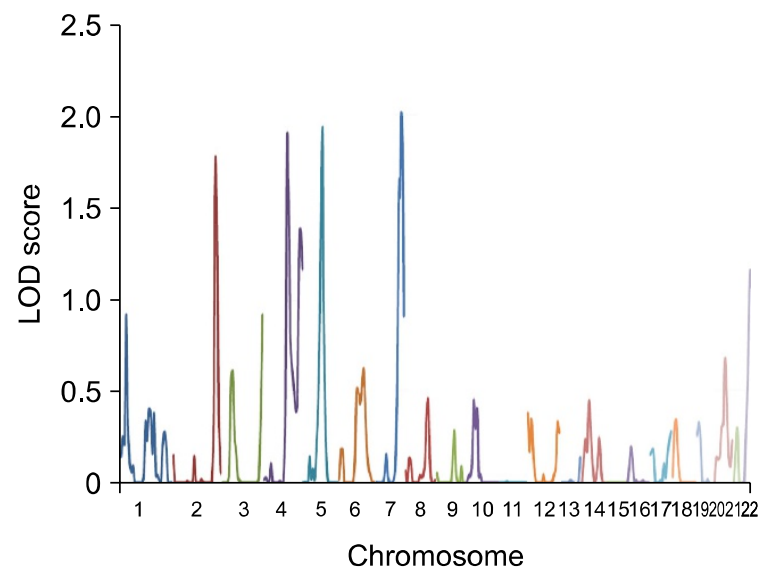

B

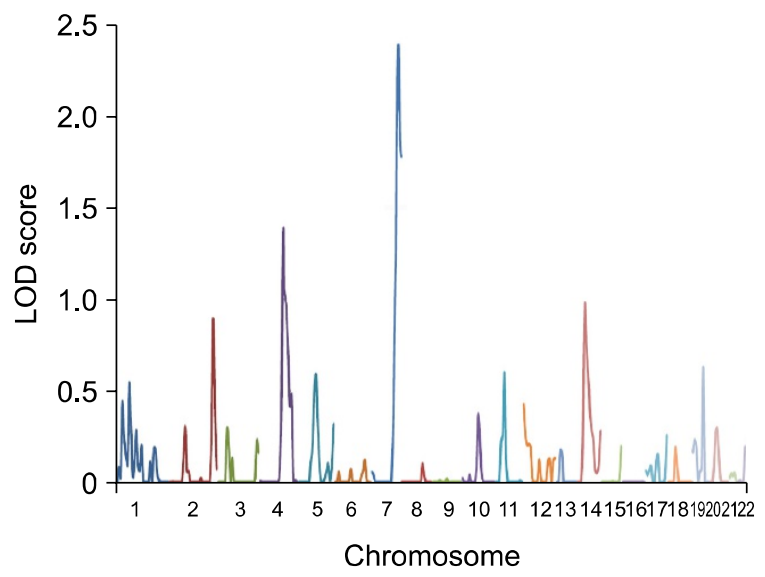

Figure 2. Results of a multipoint linkage analysis across 22 autosomes for the all ages group (A) and the adult age group (B). The horizontal line (x axis) shows 22 autosomes sequentially. The vertical line (y axis) shows multipoint LOD scores.

total cholesterol, HDL, LDL), and fasting plasma glucose are not statistically meaningful in a multiple regression analysis, suggesting these factors do not independently affect the QTc interval.

Familial correlation analysis was performed to evaluate genetic effects in the variation of the QTC interval. In this analysis, correlation of the phenotype in parent-offspring pairs and sibling-sibling pairs reflects both the familial and environmental effects, and spouse-spouse pairs reflect an environmental effect because parent-offspring pairs

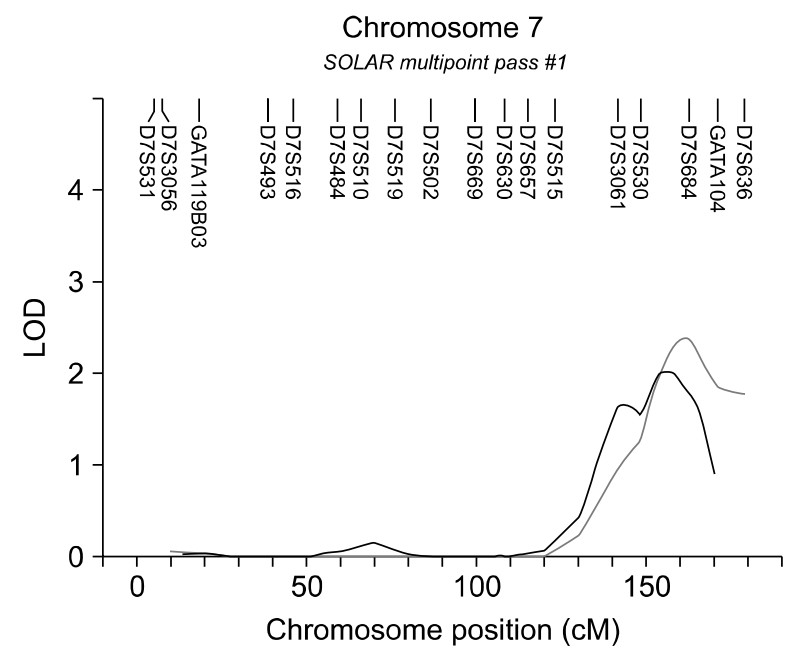

Figure 3. Results of the multipoint linkage analysis for chromosome 7. The highest peak is on chromosome 7 (maximum LOD score 2.0 in black; 2.4 in gray). The $x$ axis shows the genetic position on chromosome 7 and the y axis shows the multipoint LOD score. The upper part is the position of the markers. Black : all age group; Gray : adult group ( $\geq$ $20 \mathrm{yr})$. and sibling-sibling pairs share genetic and environmental factors while spouse-spouse pairs share only environmental factors. Therefore, our results indicate a genetic effect on the QTc interval.

Correlation in mother-son pairs is stronger than in father-son pairs, and correlation in brother-brother pairs is stronger than in sister-sister pairs. Hong et al. (2001) found similar results and suggested they are due to mitochondrial and/or pre-natal effects. However, we think it could be an X-chromosomal effect because a son has only one $\mathrm{X}$ chromosome, from his mother. Father and son do not share an $X$ chromosome while mother and son always share one. Similarly, brother-brother pairs have a lower chance of sharing an $X$ chromosome than sister-sister pairs. Brother-brother and sister-sister pairs have the same chances of receiving the same $X$ chromosome from their mother, but sister-sister pairs always share one $X$ chromosome from their father. Therefore, candidate genes could be located on the $X$ chromosome. We did not type genetic markers on the $X$ chromosome so this hypothesis could not be tested.

Genome-wide linkage analysis of the QTC interval in a general population was performed in one previous study (Newton-Cheh et al., 2005). Evidence was found suggestive of linkage of the QT interval 19 to $48 \mathrm{cM}$ from the tip of the short arm of chromosome 3 (maximum two-point LOD score 3.00, maximum multipoint LOD score 2.71). The region of linkage contains potassium and sodium channel genes, including the SCN5A gene that has been implicated in one form of the long QT syndrome. Our linkage analysis results identified peaks on different chromosomes. The regions of the highest three peaks, on chromosomes $7 q 31$, 
$5 q 21$, and $4 q 28$, contain ANK2 and ankyrin repeat genes. Most LQTS genes encode potassium or sodium channel proteins and one gene encodes the structural protein ankyrin-B, which is thought to anchor ion channels to the cellular membrane. Either a decrease in the potassium efflux due to a loss of function of the potassium channel or an increase in the sodium influx due to a gain of function of the sodium channel, is thought to be a mechanism of LQTS. Impairment of the ankyrin-B protein leads to deterioration of the channels and yields the same result. Therefore, we think that the ankyrin gene family is a strong candidate for control of the QTc interval.

We also performed an additional linkage analysis using only the adult population ( $\geq 20$ years old) (Table 7, Figure 2 and 3). The maximum LOD score of the highest peak on chromosome 7 rose to 2.4 in the adult population from 2.0 in whole population, and other peaks on chromosomes 2, 4, and 5 became smaller (Figure 2). The peak on chromosome $7 q 34$ in the adult population was located slightly closer to telomere than the previous peak in the whole population. This region contains KCND2 and $\mathrm{KCNH} 2$ genes that encode potassium voltage-gated channels. These potassium channel genes KCND2 and KCNH2 are also candidate control genes.

In conclusion, our study confirmed a genetic effect on the QTC interval, and identified four regions of potential linkage and candidate control genes in those regions. Several non-genetic factors affecting the QTc interval were identified. Further studies, such as linkage analyses covering the $\mathrm{X}$ chromosome in other populations, association studies, and biological function studies of candidate genes will elucidate details of QTC regulation. Our results can be used as a basis for future studies, and contributes to an improvement in risk assessment and treatment of ventricular arrhythmia and cardiovascular mortality.

\section{Methods}

\section{Study population and baseline measurement}

A total of 1,309 individuals from 142 families were recruited from a rural community in Selenge Province, Mongolia, as part of a GENDISCAN (GENe DIScovery for Complex traits in Asians of the Northeast) study (Gombojav et al., 2008). Study participants were members of 13 ethnic groups between 5 and 82 years of age. Basic individual information (age and sex), pedigree information, and self-reported medical histories were ascertained using questionnaires. Blood was collected from most subjects in both fasting and non-fasting states using heparin tubes. Values for total cholesterol, HDL cholesterol, LDL choles- terol, triglycerides, and glucose were measured from fasting plasma. Body weight $(\mathrm{kg})$ and height $(\mathrm{cm})$ were checked and the body mass index (BMI, $\mathrm{kg} / \mathrm{m}^{2}$ ) was calculated using the formula $\mathrm{BMI}=$ body weight/(body height $)^{2}$. After subjects rested for 5 minutes, the blood pressure (systolic blood pressure, SBP, and diastolic blood pressure, DBP) was measured by a physician using a standardized mercury sphygmomanometer, and the mean of 2 measurements was used in our analyses. Less informative subjects, such as members of small families, were excluded, after which 1,098 phenotyped subjects remained. The study was approved by an institutional review committee and the participants gave informed consent.

\section{Electrocardiogram measurement}

A standard 12-lead electrocardiogram (Bionet Co., LTD, Korea) was recorded from 1,074 subjects at a paper speed of $25 \mathrm{~mm} / \mathrm{s}$ and a gain of $10 \mathrm{~mm} / \mathrm{mV}$ and read manually by a cardiologist. The QT interval was determined as the onset of the QRS wave to the end of the T wave in lead II. The QRS duration was measured in an identical manner from the onset of the $Q$ wave to the endpoint of the $S$ wave. We used a corrected QT interval (QTc interval), which was the QT interval length corrected for heart rate using Bazett's formula of QTc=QT/(RR) ${ }^{1 / 2}$ (Bednar et al., 2001).

\section{DNA extraction and genotyping}

Leukocyte DNA was extracted from buffy coat specimens using a Gentra DNA isolation kit according to the manufacturer's protocol and we obtained at least $30 \mu \mathrm{g}$ of high purity DNA from each subject. All subjects were genotyped for 384 short tandem repeat (STR) microsatellite markers with an average spacing interval of $10 \mathrm{cM}$ (ABI co., LMS v2.5 HD10) excluding markers on the $X$ chromosome. After PCR amplification (GeneAmp PCR System 9600), multiplex running of the PCR set was performed using internal standard DNA for high efficiency and data stability (GeneScan-500 LIZ, CEPH 1347-02, ABI Prism 3730 DNA analyzer). We then determined the size of the running results and genotypes using GeneMapper software (Applied Biosystems (ABI), ver. 3.7). A total of 317 markers remained after we excluded markers with genotyping errors. The calling rate was $99.9 \%$. We added 13 markers in chromosomal areas where the inter-marker distance was larger than $25 \mathrm{cM}$ because inclusion of these areas could reduce the power of the linkage analysis. Among the genotyping-error markers, 19 markers that had inter-marker distances larger than $15 \mathrm{cM}$ were replaced with new markers. Final genotyping of 349 markers was performed in 1,080 subjects from the 1,098 phenotyped subjects.

\section{Data analysis}

Univariate analysis and multiple regression analysis were performed using SAS version 8.1 software (SAS Institute, Cary, NC). The familial correlation was analyzed using S.A.G.E. (Statistical Analysis for Genetic Epidemiology, 
http://darwin.cwru.edu/sage). IBD and MIBD matrices were calculated using the Loki package, a linkage analysis package using Markov chain Monte Carlo (MCMC) techniques (Heath, 1997). Loki supports estimation of IBD relationship matrices for use with variance component programs, such as SOLAR. Heritability estimates and multipoint linkage analysis were performed using a variance-component method implemented in the SOLAR (Sequential Oligogenic Linkage Analysis Routines) package (Almasy and Blangero, 1998).

\section{Acknowledgements}

This work was supported by a grant (M1030503000008N503-00000) from the Korean Ministry of Education, Science and Technology. Some of the results of this paper were obtained using the software package S.A.G.E., which is supported by a U.S. Public Health Service Resource Grant (RR03655) from the National Center for Research Resources.

\section{References}

Algra A, Tijssen JG, Roelandt JR, Pool J, Lubsen J. QTC prolongation measured by standard 12-lead electrocardiography is an independent risk factor for sudden death due to cardiac arrest. Circulation 1991;83:1888-94

Almasy L, Blangero J. Multipoint quantitative-trait linkage analysis in general pedigrees. Am J Hum Genet 1998;62: 1198-211

Bednar MM, Harrigan EP, Anziano RJ, Camm AJ, Ruskin JN. The QT interval. Prog Cardiovasc Dis 2001;43:1-45

Benoit SR, Mendelsohn AB, Nourjah P, Staffa JA, Graham DJ. Risk factors for prolonged QTc among US adults: Third National Health and Nutrition Examination Survey. Eur J Cardiovasc Prev Rehabil 2005;12:363-8

Busjahn A, Knoblauch $H$, Faulhaber HD, Boeckel $T$, Rosenthal M, Uhlmann R, Hoehe M, Schuster H, Luft FC. QT interval is linked to 2 long-QT syndrome loci in normal subjects. Circulation 1999;99:3161-4

Carter N, Snieder H, Jeffery S, Saumarez R, Varma C, Antoniades L, Spector TD. QT interval in twins. J Hum Hypertens 2000;14:389-90

Crow RS, Hannan PJ, Folsom AR. Prognostic significance of corrected QT and corrected JT interval for incident coronary heart disease in a general population sample stratified by presence or absence of wide QRS complex: the ARIC Study with 13 years of follow-up. Circulation 2003; 108:1985-9

de Bruyne MC, Hoes AW, Kors JA, Hofman A, van Bemmel $\mathrm{JH}$, Grobbee DE. Prolonged QT interval predicts cardiac and all-cause mortality in the elderly. The Rotterdam Study. Eur Heart J 1999;20:278-84

Dekker JM, Crow RS, Hannan PJ, Schouten EG, Folsom AR. Heart rate-corrected QT interval prolongation predicts risk of coronary heart disease in black and white middle-aged men and women: the ARIC study. J Am Coll Cardiol 2004;43:
$565-71$

Dekker JM, Schouten EG, Klootwijk P, Pool J, Kromhout D. Association between QT interval and coronary heart disease in middle-aged and elderly men. The Zutphen Study. Circulation 1994;90:779-85

Friedlander Y, Lapidos T, Sinnreich R, Kark JD. Genetic and environmental sources of QT interval variability in Israeli families: the kibbutz settlements family study. Clin Genet 1999;56:200-9

Garson A, Jr. How to measure the QT interval--what is normal? Am J Cardiol 1993;72:14B-16B

Goldberg RJ, Bengtson J, Chen ZY, Anderson KM, Locati E, Levy D. Duration of the QT interval and total and cardiovascular mortality in healthy persons (The Framingham Heart Study experience). Am J Cardiol 1991; 67:55-8

Gombojav B, Park H, Kim JI, Ju YS, Sung J, Cho SI, Lee MK, Ohrr H, Radnaabazar J, Seo JS. Heritability and linkage study on heart rates in a Mongolian population. Exp Mol Med 2008;40:558-64

Grandinetti A, Seifried S, Mor J, Chang HK, Theriault AG. Prevalence and risk factors for prolonged QTc in a multiethnic cohort in rural Hawaii. Clin Biochem 2005;38:116-22

Heath SC. Markov chain Monte Carlo segregation and linkage analysis for oligogenic models. Am J Hum Genet 1997;61:748-60

Hong Y, Rautaharju PM, Hopkins PN, Arnett DK, Djousse L, Pankow JS, Sholinsky P, Rao DC, Province MA. Familial aggregation of QT-interval variability in a general population: results from the NHLBI Family Heart Study. Clin Genet 2001;59:171-7

Jiang C, Atkinson D, Towbin JA, Splawski I, Lehmann MH, Li H, Timothy K, Taggart RT, Schwartz PJ, Vincent GM, et al. Two long QT syndrome loci map to chromosomes 3 and 7 with evidence for further heterogeneity. Nat Genet 1994;8:141-7

Keating M, Atkinson D, Dunn C, Timothy K, Vincent GM, Leppert M. Linkage of a cardiac arrhythmia, the long QT syndrome, and the Harvey ras-1 gene. Science 1991a; 252:704-6

Keating M, Dunn C, Atkinson D, Timothy K, Vincent GM, Leppert M. Consistent linkage of the long-QT syndrome to the Harvey ras- 1 locus on chromosome 11. Am J Hum Genet 1991b;49:1335-9

Liu W, Yang J, Hu D, Kang C, Li C, Zhang S, Li P, Chen Z, Qin X, Ying K, Li Y, Li Y, Li Z, Cheng X, Li L, Qi Y, Chen S, Wang Q. KCNQ1 and KCNH2 mutations associated with long QT syndrome in a Chinese population. Hum Mutat 2002;20: 475-6

Mangoni AA, Kinirons MT, Swift CG, Jackson SH. Impact of age on QT interval and QT dispersion in healthy subjects: a regression analysis. Age Ageing 2003;32:326-31

Newton-Cheh C, Larson MG, Corey DC, Benjamin EJ, Herbert AG, Levy D, D'Agostino RB, O'Donnell CJ. QT interval is a heritable quantitative trait with evidence of 
linkage to chromosome 3 in a genome wide linkage analysis: The Framingham Heart Study. Heart Rhythm 2005;2:277-84

Peters RW, Byington RP, Barker A, Yusuf S. Prognostic value of prolonged ventricular repolarization following myocardial infarction: the BHAT experience. The BHAT Study Group. J Clin Epidemiol 1990;43:167-72

Reardon M, Malik M. QT interval change with age in an overtly healthy older population. Clin Cardiol 1996;19:949-52

Russell MW, Law I, Sholinsky P, Fabsitz RR. Heritability of ECG measurements in adult male twins. J Electrocardiol 1998;30 Suppl:64-8

Schott JJ, Charpentier F, Peltier S, Foley P, Drouin E, Bouhour JB, Donnelly P, Vergnaud G, Bachner L, Moisan JP, et al. Mapping of a gene for long QT syndrome to chromosome 4q25-27. Am J Hum Genet 1995;57:1114-22

Schouten EG, Dekker JM, Meppelink P, Kok FJ, Vandenbroucke JP, Pool J. QT interval prolongation predicts cardiovascular mortality in an apparently healthy population. Circulation 1991;84:1516-23
Shah M, Akar FG, Tomaselli GF. Molecular basis of arrhythmias. Circulation 2005;112:2517-29

Siscovick DS, Raghunathan TE, Rautaharju P, Psaty BM, Cobb LA, Wagner EH. Clinically silent electrocardiographic abnormalities and risk of primary cardiac arrest among hypertensive patients. Circulation 1996;94:1329-33

Splawski I, Shen J, Timothy KW, Lehmann MH, Priori S, Robinson JL, Moss AJ, Schwartz PJ, Towbin JA, Vincent GM, Keating MT. Spectrum of mutations in long-QT syndrome genes. KVLQT1, HERG, SCN5A, KCNE1, and KCNE2. Circulation 2000;102:1178-85

Vitelli LL, Crow RS, Shahar E, Hutchinson RG, Rautaharju $\mathrm{PM}$, Folsom AR. Electrocardiographic findings in a healthy biracial population. Atherosclerosis Risk in Communities (ARIC) Study Investigators. Am J Cardiol 1998;81:453-9

Wang Q, Shen J, Splawski I, Atkinson D, Li Z, Robinson JL, Moss AJ, Towbin JA, Keating MT. SCN5A mutations associated with an inherited cardiac arrhythmia, long QT syndrome. Cell 1995;80:805-11 


\section{Erratum}

Sun-Wha $\mathrm{Im}^{1}$, Mi Kyeong Lee ${ }^{2,3}$, Hee Jeong Lee ${ }^{3}$, Se-ll Oh ${ }^{4}$, Hyung-Lae Kim ${ }^{5}$, Joohon Sung ${ }^{3}$, Sung-II Cho ${ }^{3}$, Jeong-Sun Seo ${ }^{1,6,7}$ and Jong-II Kim ${ }^{1,2,6,7}$

Analysis of genetic and non-genetic factors that affect the QTc interval in a Mongolian population: the GENDISCAN study

Exp Mol Med 2009;41:841-848

The authors regret an error in discussion, the authors wrote that "We also performed an additional linkage analysis using only the adult population ( $\geq 20$ years old)(Table 7, Figure 2 and 3)." In this sentence, Table 7 should be changed to Table 6 .

The authors apologize for any inconvenience this mistake may have caused. 